\title{
PRIMER UPORABE GIS-a V TOPOKLIMATSKI ANALIZI POKRAJINE ZA POTREBE VINOGRADNIŠTVA
}

\author{
Igor Žiberna
}

\section{Izvleček}

$\mathrm{Za}$ potrebe analize leg vinogradniških pouršin in spreminjanja vinogradniških pouršin med leti 1824 in 1985 smo izdelali preprost GIS za due sondni območji $v$ Srednjih Slovenskih goricah. GIS je kot osnouno ploskev uporabil mrežo DMR $50 \times 50 \mathrm{~m}$. S pomočjo nekaterih topoklimatskih podatkov smo poskušali izdelati karto klimatsko primernih območij za vinsko trto. Prikazane so tudi spremembe vinogradniških pouršin med leti 1824 in 1985.

UDC $634.8: 91: 681.3$

\section{Abstract \\ THE APPLICATION OF GIS IN THE TOPOCLIMATIC ANALYSIS \\ OF THE LANDSCAPE FOR NEEDS OF VITICULTURE}

For the needs of the analysis of the positions of viticulture areas and thechanges between the years 1824 and 1985 we have made a simple GIS for two example areas in the Middle Slovenske gorice. The DEM $50 \times 50 \mathrm{~m}$ was used for GIS as a basic data layer. With the help of certain topoclimatical data we have tried to make a map of climatical conveniend areas for the vineyard. The changes of viticultural areas between the years 1824 and 1985 are shown as well.

\section{PREDSTAVITEV METODOLOGIJE}

Glede na to, da je relief eden od glavnih modifikatorjev klime $v$ razgibanem svetu, nas je zanimalo, v kakšni meri so vinogradniške površine odvisne od nekaterih, recimo jim topoklimatskih kazalcev (absolutne in relativne nadmorske višine, naklon, ekspozicija) in ostalih, od morfometrije odvisnih kazalcev (globalno sončno obsevanje, bonitete vinogradniških površin). Naklon in ekspozicija modificirata klimo gričevja zlasti podnevi, medtem ko ponoči in zjutraj igra pomembno vlogo relativna višina (Geiger, 1966; Geiger, 1969).

Vinogradniške lege, s tem pa tudi topoklimatske značilnosti le-teh smo ugotavljali s pomočjo Digitalnega modela reliefa. Pri tem smo uporabili programa DMR (IGF) in IDRISI.

Mag. Igor Žiberna, prof. geogr., Oddelek za geografijo, Pedagoška fakulteta, Maribor, Slovenija 
Tudi v našem primeru seveda nismo mogli mimo dileme o velikosti osnovne celice DMR. Odločili smo se, da bomo testirali uporabnost DMR $100 \mathrm{x}$ 100 z natančnejšim DMR 50 × 50, katerega bazo podatkov smo izdelali sami. Kot testno območje smo izbrali del Radgonsko - Kapelskih goric v zaledju G.Radgone (Police). Bat (1989) in Gabrovec (1989) sta za hriboviti svet (Martinj Vrh nad Selško dolino in Tirosek nad Zadrečko dolino) že opravila podobno testiranje, pri čemer sta primerjala razlike $v$ naklonih. Prav zato so lahko naši rezultati, ki govorijo o zanesljivosti DMR 100 x $100 \mathrm{v}$ gričevnatem svetu, še posebej uporabni.

V našem primeru smo naklone najprej izračunali iz vogalnih točk DMR $50 \times 50$, naklon $v$ celici $100 \times 100 \mathrm{~m}$ pa smo dobili iz povprečja naklonov štirih celic $50 \times 50 \mathrm{~m}$ v njej. Po drugi strani pa smo upoštevali vsako drugo točko DMR 50 × 50 in tako naklone v hektarski celici izračunali direktno iz štirih vogalnih točk. Razlike med nakloni po obeh metodah so za vse tri sonde naslednje:

Tabela 1: Razlike med nakloni, dobljenimi s pomočjo DMR 100x100 IN DMR $50 \times 50$.

\begin{tabular}{|l|l|l|r||}
\hline \hline SONDNO OBMOČJE & NAD 1 & NAD 2 & POD 5 \\
\hline Tirosek & $61.2 \%$ & $83.4 \%$ & $4.4 \%$ \\
Martinj Vrh & $50.8 \%$ & $72.8 \%$ & $7.8 \%$ \\
Police & $43.1 \%$ & $61.8 \%$ & $10.8 \%$ \\
\hline
\end{tabular}

Iz Tabele 1 je razvidno, da je DMR 100 x 100 v gričevnati pokrajini manj veren kot $\mathbf{v}$ hriboviti pokrajini. To je bil tudi eden od argumentov, da smo se odločili za DMR 50 × 50 m.

V vinogradniški pokrajini Srednjih Slovenskih goric smo izbrali dve sondni območji. Prvo sondno območje predstavlja že omenjeno območje v Radgonsko-Kapelskih goricah (Police), veliko 3 x 4 km (4800 celic). Drugo sondno območje je območje Mestnega Vrha in Gomile v Ptujskih goricah, veliko 2 x $2 \mathrm{~km}$ (1600 celic), kjer se sicer še pojavljajo vinogradniški kompleksi, vendar pa vinogradništvo tu ni osnovna kmetijska dejavnost.

Izdelali smo preprosti GIS z naslednjimi sloji :

- absolutna nadmorska višina (ANV)

- relativna višina (REV)

- naklon (NAK)

- ekspozicija (EKS)

- globalno sončno obsevanje (GSO)

- bonitete vinogradniških površin (BON)

- vinogradniške površine leta 1824 (V84)

- vinogradniške površine leta 1985 (V85). 
Morfometrijske elemente (absolutno nadmorsko višino, relativno višino, naklon in ekspozicijo) smo računali s pomočjo programa IDRISI.

Globalno sončno obsevanje kot vsoto direktnega in difuznega sončnega obsevanja smo izračunali s pomočjo modela, ki sta ga izdelala Hočevar in Rakovec $(1978,1979)$ :

\section{DIREKTNO SONČNO OBSEVANJE :}

$$
D I R=r^{2} \cdot I \cdot(q a \cdot q s)^{m} \cdot D \sin (p)
$$

DIFUZNO SONČNO OBSEVANJE :

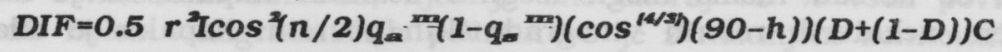

\section{GLOBALNO SONČNO OBSEVANJE :}

\section{GSO $=D I R+D I F$}

Pri tem pomenijo :

r - faktor, ki nam kaže spremembo solarne konstante zaradi različne oddaljenosti Zemlje od Sonca. Podatek povzet po astronomskih efemeridah.

I - solarna konstanta $\left(I=1.35 \mathrm{~kW} / \mathrm{m}^{2}\right)$

$\mathrm{q}_{\mathrm{a}}$ in $\mathrm{q}_{\mathrm{s}}$ - transmisijska koeficienta glede na absorpcijo in razpršitev $\mathrm{v}$ atmosfero (oba w 0.90)

m - optična zračna masa (= sekans zenitnega kota Sonca $z$ )

D - relativno trajanje sončnega obsevanja $\mathrm{v}$ določenem časovnem intervalu

C - faktor, odvisen od rodu oblakov in zenitnega kota Sonca $\left(z=90^{\circ}-h\right)$.

Za obdobje vegetacije vzamemo kot tipičen oblak altocumulus (Ac) :

$\mathrm{C}_{(\mathrm{AC})}=1.35+5.42 \mathrm{z}-3.38 \mathrm{z} 2$

p - kot med sončnim žarkom in pobočjem, ki ga izračunamo :

$\sin p=(\sin (g) \cdot \cos (n)-\cos (g) \cdot \sin (n) \cdot \cos (a)) \cdot \sin (d)+(\cos (g) \cdot \cos (n)+\sin (g) \cdot$ $\sin (n) \cdot \cos (a)) \cdot \cos (d) z \cos (t)+\sin (n) \cdot \sin (a) \cdot \cos (d) \cdot \sin (t)$

pri čemer pomenijo :

g - geografska širina kraja

d - deklinacija Sonca (podatek iz Astronomskih efemerid)

n - naklon pobočja oz.celice

a - azimut pobočja oz.celice

t - urni kot Sonca (t $=0$ ob 12.uri)

h - višina Sonca izračunana po formuli :

$\sin (\mathrm{h})=\sin (\mathrm{g}) \cdot \sin (\mathrm{d})+\cos (\mathrm{g}) \cdot \cos (\mathrm{d}) \cdot \cos (\mathrm{t})$.

(Hočevar, Rakovec, 1978; Hočevar, Rakovec, 1979).

Glede na to, da smo za oblačnost razpolagali le s podatki za devet meteoroloških postaj, smo člen, ki govori o relativnem trajanju sončnega obse- 
vanja zanemarili. Pri tem smo sicer naredili določeno napako, saj smo dejansko izračunali potencialno globalno sončno obsevanje in s tem precenili globalno sončno obsevanje $\mathrm{v}$ nižinah. Tu se na začetku in koncu vegetacijskega obdobja pogosteje pojavlja megla kot $v$ termalnem pasu, kar zmanjša vrednost globalnega sončnega obsevanja. Vendar pa smo pri bonifikacijah upoštevali relativno višino celice in na ta način omenjeno napako odpravili.

Vinogradniške površine za leto 1824 smo določali s pomočjo kart franciscejskega katastra za ustrezne katastrske občine. Pri tem smo karto vinogradniških površin prekrili z mrežo kvadratov 50 × $50 \mathrm{~m}$ in izločili tiste kvadrate, kjer so vinogradniške površine prekrile vsaj polovico kvadrata. Pri tem se seveda nismo mogli izogniti določeni napaki, ki je nastala $z$ izločanjem nekaterih robnih vinogradniških površin. Napaka je bila manjša tam, kjer smo analizirali večje vinogradniške komplekse (ti so praviloma v družbeni lasti), večja pa pri analizi majhnih razdrobljenih vinogradniških površin, (ki so največkrat v zasebni lasti), saj se nam je marsikatera vinogradniška parcela v tako velikih celicah "izgubila".

Vinogradniške površine za leto 1985 smo določali s pomočjo TTN v merilu 1 : 5000 in aerofotoposnetkov za ustrezno območje.

Primerjali smo tudi vinogradniške lege $v$ obeh obdobjih. V zvezi $s$ tem nas je zanimalo, v kakšnih legah je prišlo do sprememb (opuščanja) vinogradniških površin.

Bonitete vinogradniških površin smo določali s pomočjo prekrivanja več slojev GIS-a. Predvsem smo upoštevali globalno sončno obsevanje, v katerem so posredno izraženi nakloni in ekspozicije celic ter relativne višine. Pri slednjih smo upoštevali, da se nad $50 \mathrm{~m}$ relativne višine slana pojavlja redkeje (Gams, 1972a; Gams, 1972b). Ugotovitve je potrjevalo tudi anketiranje na terenu. Pas med 25 in $50 \mathrm{~m}$ relativne nadmorske višine so domačini pogosto opisovali kot pas, kjer se slana sicer še pojavlja, vendar redkeje in manj intenzivno. Potrebno pa je opozoriti, da ima vsaka dolina svoje morfološke značilnosti in $s$ tem tudi posebnosti glede pojavljanja sla-

Tabela 2 .

\begin{tabular}{|c|c|c|}
\hline $\begin{array}{l}\text { BONITETNI } \\
\text { RAZRED }\end{array}$ & $\begin{array}{c}\text { GLOBALNO SONČNO OBSEVANJE } \\
\left(\mathrm{kWn} / \mathrm{m}^{2}\right)\end{array}$ & $\begin{array}{c}\text { RELATIVNA VIŠINA } \\
(\mathbf{m})\end{array}$ \\
\hline 1. & NAD 900 & NAD 50 \\
\hline 2. & $800-900$ & NAD 50 \\
\hline 3. & NAD 900 & $25-50$ \\
\hline 4. & $800-900$ & $25-50$ \\
\hline 5. & POD 800 & NAD 50 \\
\hline 6. & OSTALO & \\
\hline
\end{tabular}


ne. Spomnimo naj, da taka bonifikacija upošteva le klimatske elemente, ne upošteva pa geološke podlage in tipa prsti, niti nekaterih družbenogeografskih dejavnikov (bližina komunikacij, vinskih kleti ipd.). Bonitete vinogradniških površin s klimatskega vidika so na tabeli 2 .

\section{TOPOKLIMATSKE ZNAC̆ILNOSTI VINOGRADNIŠKIH POVRS̆IN NA SONDNIH OBMOČJIH POLICE IN MESTNI VRH}

\section{SONDNO OBMOČJE POLICE}

Deleži vinogradniških površin glede na bonitete leta 1824 so bili najvišji v prvem bonitetnem razredu, kjer je bilo skoraj $75 \%$ vseh površin pod vinogradi. Delež vinogradniških površin se je $z$ nižanjem bonitetnih razredov manjšal. Zlasti izrazit je skok med drugim in tretjim bonitetnim razredom. C̆e so $v$ drugem razredu vinogradniške površine pokrivale $60 \%$ površja, je njihov delež $v$ tretjem bonitetnem razredu padel na $37 \%$ (Tabela 3). Zanimivo pa je, da je delež vinogradniških površin v petem bonitetnem razredu ponovno porasel na skoraj $39 \%$. V tem primeru gre za površine, katerih relativna višina je nad $50 \mathrm{~m}$, v vegetacijski dobi pa prejmejo manj kot $800 \mathrm{kWh} / \mathrm{m}^{2}$. To so območja, ki so manj izpostavljena slani, zaradi manjšega naklona ali manj primerne ekspozicije pa $\mathrm{v}$ vegetacijski dobi prejmejo manj energije. Gre torej za vinogradniške površine na grebenih ali na severnih pobočjih.

Vinogradniške površine so leta 1985 v prvem bonitetnem razredu še vedno pokrivale $53 \%$ vseh površin v tem razredu. Njihov delež se je postop-

Slika 1: Vinogradniške pouršine na sondnem območju Police leta 1824.

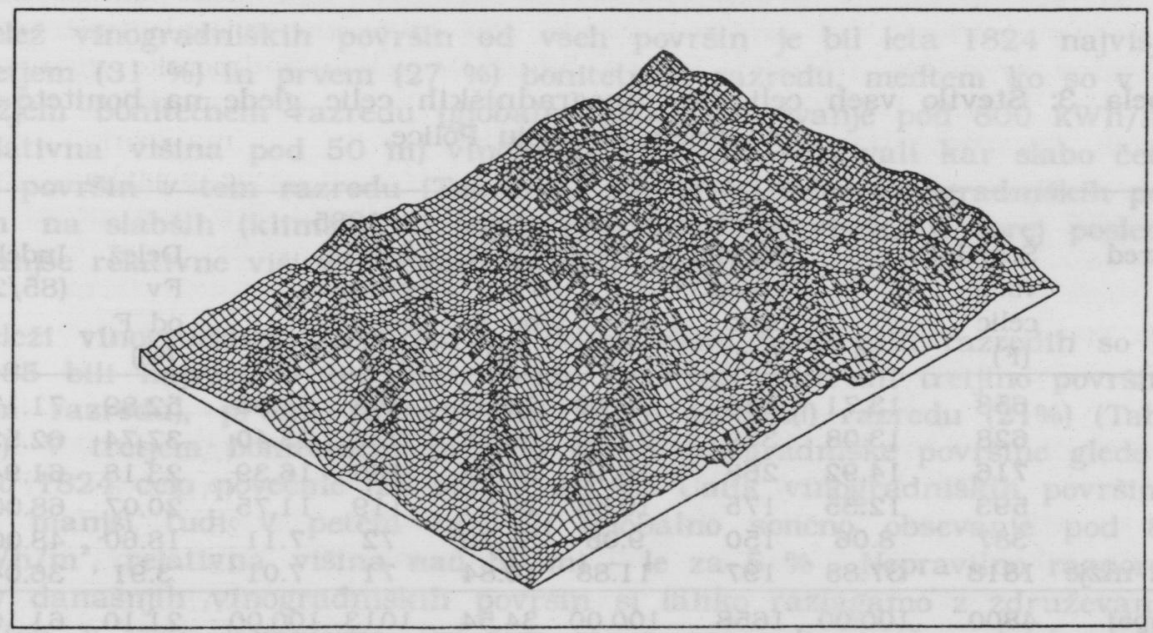


no zmanjševal s padanjem kvalitete vinogradniških površin. Medtem ko v petem bonitetnem razredu vinogradi še vedno pokrivajo skoraj petino površin $v$ tem razredu, pa njihov delež $v$ najnižjem razredu pade na $4 \%$. Umik vinogradov $v$ omenjenem obdobju je bil najmanjši v prvem bonitetnem razredu, kjer se je delež vinogradov zmanjšal le za $29 \%$. Nekoliko večji je bil umik vinogradov $v$ drugem in tretjem bonitetnem razredu (za okoli $38 \%)$. Relativno majhno zmanjšanje vinogradniških površin v četrtem bonitetnem razredu (le za $32 \%$ ) gre pripisati ohranjanju vinogradov na manjših strminah.

Slika 2: Vinogradniške pouršine na sondnem območju Police leta 1985.

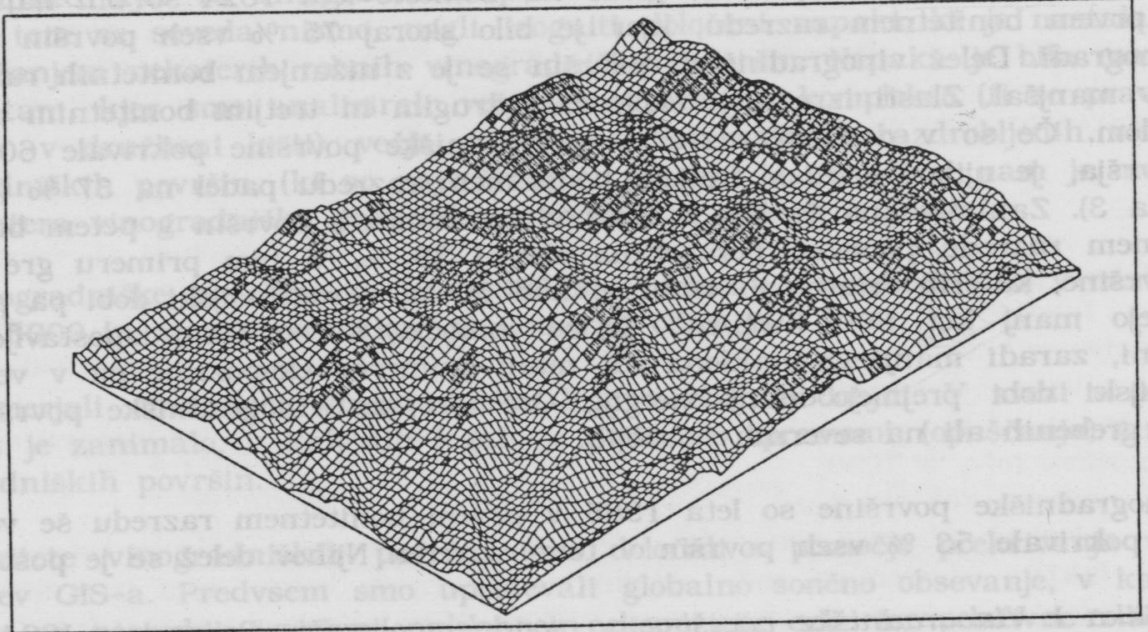

Tabela 3: Število vseh celic in vinogradniških celic glede na bonitete na sondnem območju Police.

\begin{tabular}{|c|c|c|c|c|c|c|c|c|c|c|}
\hline Razr & ed & $\begin{array}{l}\text { Stevilo } \\
\text { vseh } \\
\text { celic } \\
\text { (F) }\end{array}$ & $\%$ & $\begin{array}{l}1824 \\
\text { Stevilo } \\
\text { vinog. } \\
\text { celic } \\
\text { (Fv) }\end{array}$ & $\%$ & $\begin{array}{l}\text { Delež } \\
\text { Fv } \\
\text { od F } \\
(\%)\end{array}$ & $\begin{array}{l}\quad 1985 \\
\text { Število } \\
\text { vinog. } \\
\text { celic } \\
\text { (Fv) }\end{array}$ & $\%$ & $\begin{array}{l}\text { Delež } \\
\text { Fv } \\
\text { od F } \\
(\%)\end{array}$ & $\begin{array}{l}\text { Indeks } \\
(85 / 24)\end{array}$ \\
\hline $\begin{array}{l}1 . \\
2 . \\
3 . \\
4 . \\
5 . \\
6 . i n\end{array}$ & nižje & $\begin{array}{c}658 \\
628 \\
716 \\
593 \\
387 \\
1818 \\
\end{array}$ & $\begin{array}{c}13.71 \\
13.08 \\
14.92 \\
12.35 \\
8.06 \\
37.88 \\
\end{array}$ & $\begin{array}{l}489 \\
379 \\
268 \\
175 \\
150 \\
197 \\
\end{array}$ & $\begin{array}{c}29.49 \\
22.86 \\
16.16 \\
10.55 \\
9.05 \\
11.88 \\
\end{array}$ & $\begin{array}{l}74.32 \\
60.35 \\
37.43 \\
29.51 \\
38.76 \\
10.84 \\
\end{array}$ & $\begin{array}{c}348 \\
237 \\
166 \\
119 \\
72 \\
71 \\
\end{array}$ & $\begin{array}{c}34.35 \\
23.40 \\
16.39 \\
11.75 \\
7.11 \\
7.01 \\
\end{array}$ & $\begin{array}{c}52.89 \\
37.74 \\
23.18 \\
20.07 \\
18.60 \\
3.91 \\
\end{array}$ & $\begin{array}{l}71.17 \\
62.53 \\
61.94 \\
68.00 \\
48.00 \\
36.04 \\
\end{array}$ \\
\hline Skup & & 4800 & 100.00 & 1658 & 100.00 & 34.54 & 1013 & 100.00 & 21.10 & 61.10 \\
\hline
\end{tabular}


Ugotovili smo že, da so vinogradniške površine $v$ obeh obravnavanih obdobjih kazale precejšnjo odvisnost od relativne nadmorske višine in naklona. Vinogradniške površine so manj odvisne od ekspozicije in $s$ tem posredno tudi od globalnega sončnega obsevanja. Kot posledica omenjenega je tudi zveza med deležem vinogradniških površin in bonitetami (s klimatskega vidika), ki je precej manjša kot bi sprva pričakovali.

Slika 3: Vinogradniške pouršine na sondnem območju Mestni Vrh leta 1824.

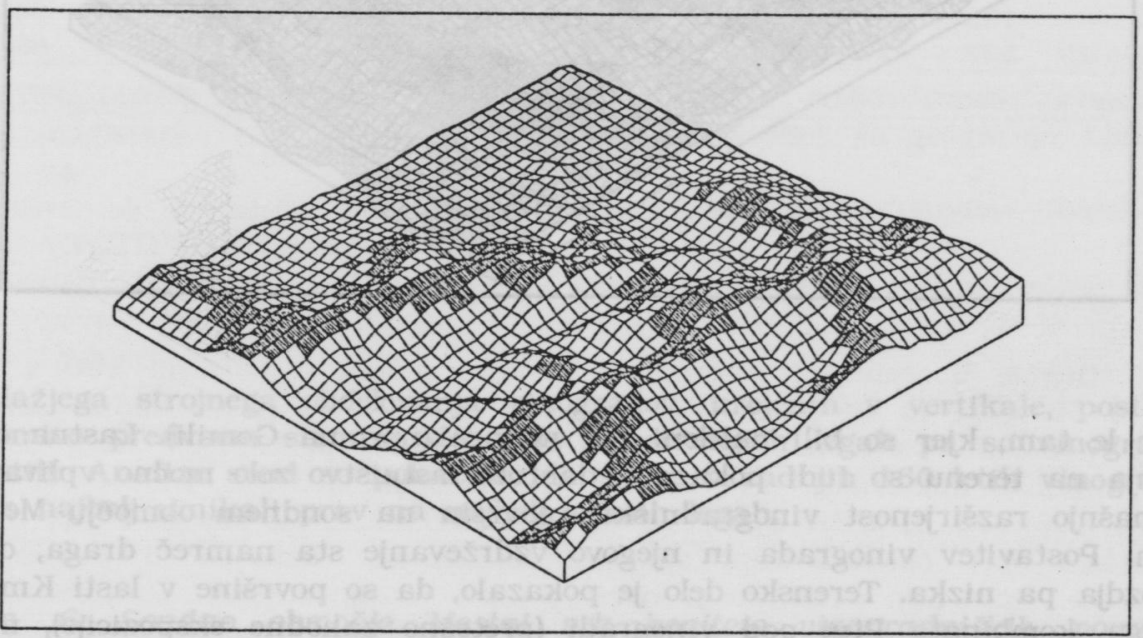

Delež vinogradniških površin od vseh površin je bil leta 1824 najvišji v tretjem (31 \%) in prvem $(27 \%)$ bonitetnem razredu, medtem ko so $v$ najnižjem bonitetnem razredu (globalno sončno obsevanje pod $800 \mathrm{kWh} / \mathrm{m}^{2}$, relativna višina pod $50 \mathrm{~m}$ ) vinogradi še vedno pokrivali kar slabo četrtino površin $v$ tem razredu (Tabela 4). Da je bil delež vinogradniških površin na slabših (klimatskih) legah nepričakovano visok, je torej posledica manjše relativne višine in manj ugodnih ekspozicij).

Deleži vinogradniških površin po (klimatskih) bonitetnih razredih so leta 1985 bili največji $v$ tretjem razredu (kjer so pokrivali tretjino površin $v$ tem razredu), prvem razredu $(23 \%)$ in šestem $(!)$ razredu $(21 \%)$ (Tabela 84). V tretjem bonitetnem razredu so se vinogradniške površine glede na leto 1824 celo povečale (za dobrih $12 \%$ ). Umik vinogradniških površin je bil manjši tudi $v$ petem razredu (globalno sončno obsevanje pod 800 $\mathrm{kWh} / \mathrm{m}^{2}$, relativna višina nad $50 \mathrm{~m}$ ) - le za $5 \%$. Nepravilno razporeditev današnjih vinogradniških površin si lahko razlagamo $z$ združevanjem le-teh v večje komplekse. Pri tem so za ceno ekonomične obdelave širili vinogradniške površine predvsem $v$ manj ugodne severne ekspozicije, ven- 
Slika 4: Vinogradniške pouršine na sondnem območju Mestni Vrh leta 1985.

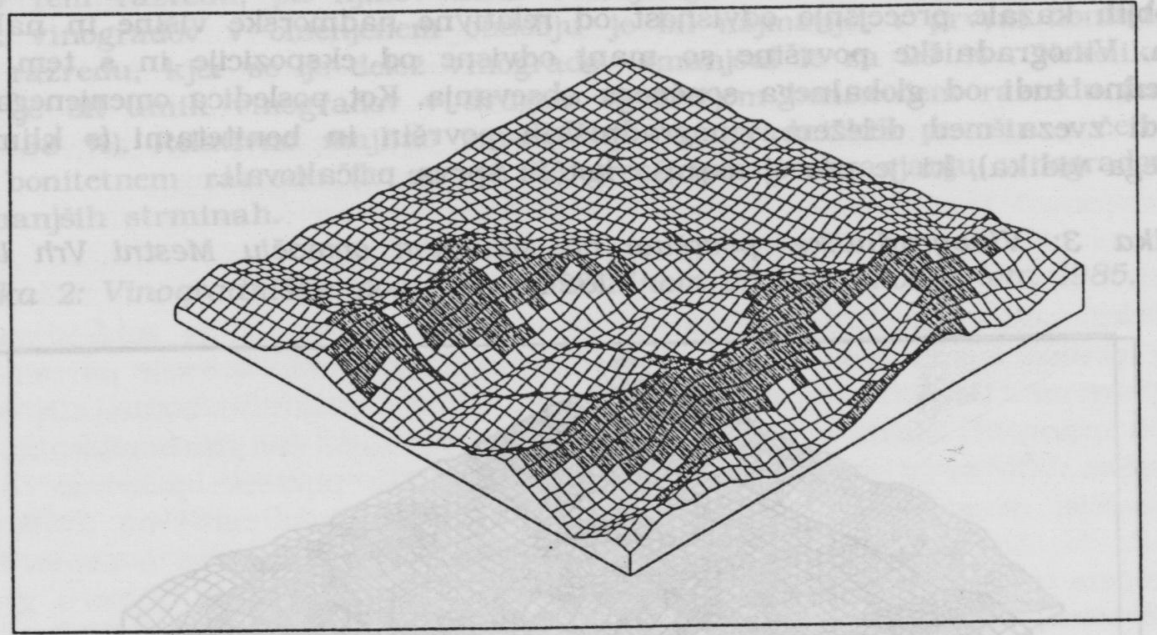

dar le tam, kjer so bili nakloni teh majhni (npr. na Gomili). Lastna opažanja na terenu so tudi pokazala, da tudi lastništvo zelo močno vpliva na današnjo razširjenost vinogradniških površin na sondnem območju Mestni Vrh. Postavitev vinograda in njegovo vzdrževanje sta namreč draga, cena grozdja pa nizka. Terensko delo je pokazalo, da so površine v lasti Kmetijskega kombinata Ptuj pod vinogradi (pretežno zahodne ekspozicije), medtem ko so površine $v$ družbeni lasti na majhnih naklonih pod njivami, na večjih naklonih pa pod sadovnjaki, saj je postavitev in vzdrževanje vinograda predrago. Gozdovi, ki na vzhodnih pobočjih Gomile segajo zelo visoko, so v lasti Gozdnega gospodarstva Ptuj, ki pa ni pripravljeno odstopiti teh, za vinsko trto klimatsko ugodnih leg.

Sklenemo torej lahko, da na sondnem območju Mestni Vrh posamezni topoklimatski elementi, predvsem relativna višina in naklon sicer vplivajo na razširjenost vinogradniških površin, da pa igrajo znotraj termalnega pasu pomembno vlogo družbenogeografski dejavniki, zlasti lastništvo zemljišč.

Analiza vinogradniških leg $v$ Srednjih Slovenskih goricah je pokazala, da trditev, po kateri bi vinogradi zavzemali predvsem strme in južne ekspozicije, ne drži vedno. To velja zlasti za vinogradniške površine v lasti družbenega sektorja. Slednji je za ceno bolj ekonomičnega obdelovanja težil k ustvarjanju večjih vinogradniških kompleksov, pri čemer so postale zanimive tudi lege, ki prejmejo bodisi manj sončnega obsevanja (torej $z$ manjšim naklonom ali klimatsko manj ugodno ekspozicijo), ali pa imajo neugodno relativno višino. Izrazit primer so Radgonsko-Kapelske gorice, kjer so zara- 
Slika 5: Sondno območje Police bonitete vinogradniških pouršin (DRM 50 $x$ 50).

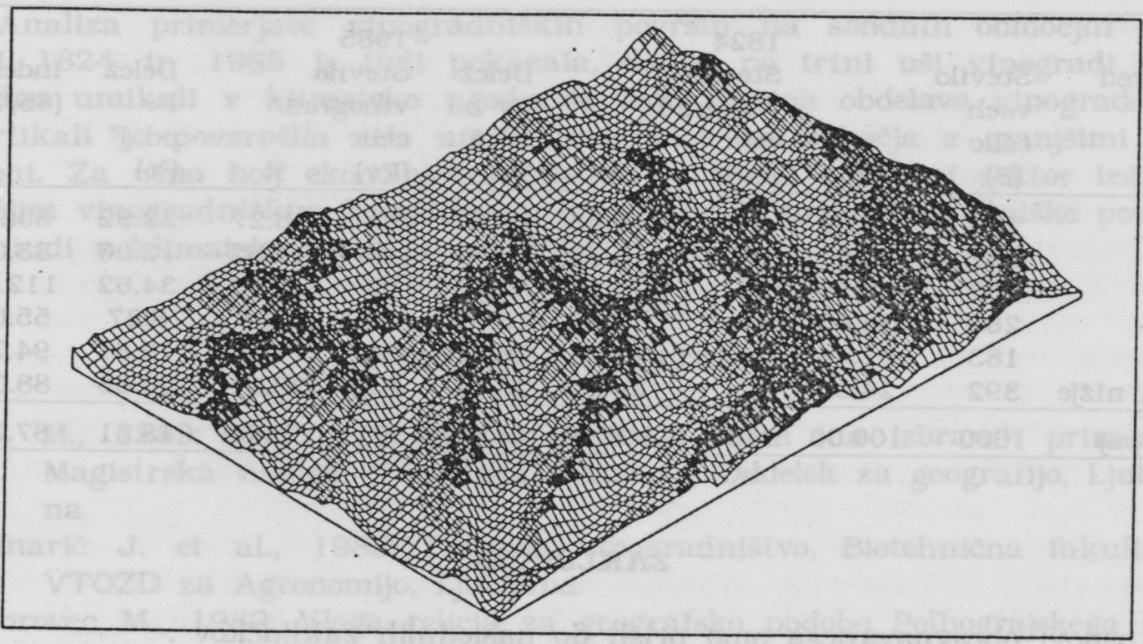

di lažjega strojnega obdelovanja vinogradov, urejenih v vertikale, postale zanimive predvsem strmine do $15 x$, na strmejših legah pa so vinograde opustili. Analize sond so pokazale, da so se v zadnjih 160 letih vinogradi često najbolj umikali prav na najbolj strmih legah.

Slika 6: Sondno območje Mestni urh bonitete vinogradniških pouršin (DRM $50 \times 50)$.

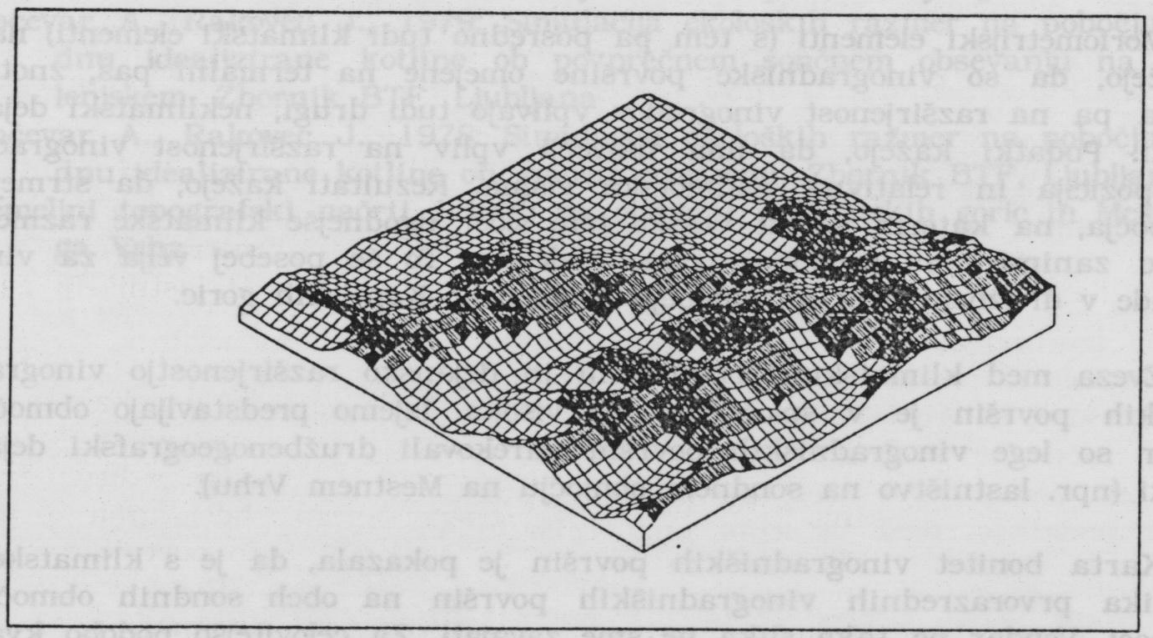


Tabela 4: Število vseh celic in vinogradniških celic glede na bonitete na sondnem območju Mestni vrh.

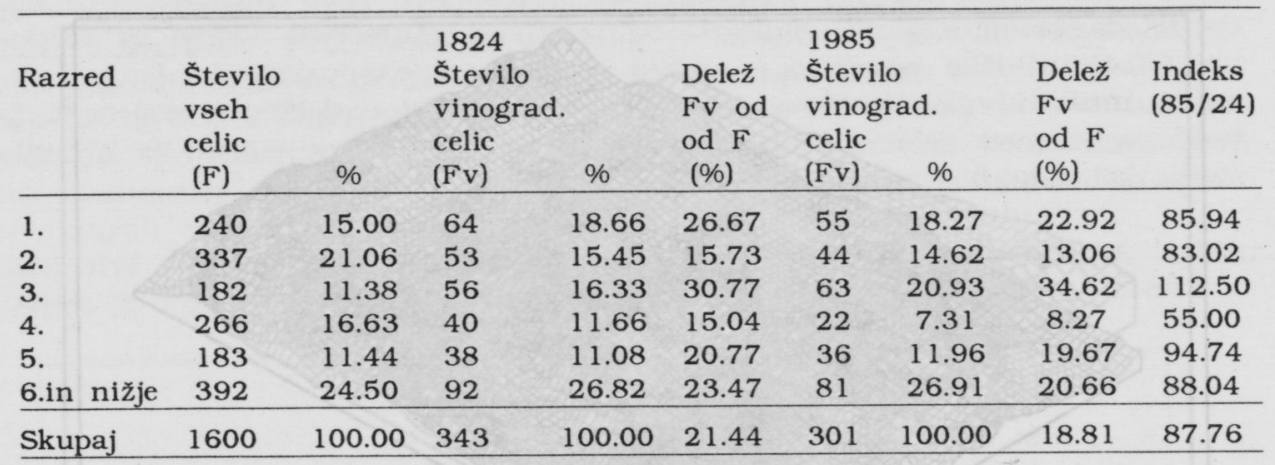

\section{ZAKLJUČKI}

Na osnovi obravnavanega smo prišli do naslednjih zaključkov :

1. Testiranje uporabnosti digitalnega modela reliefa s celicami $100 \times 100$ $\mathrm{m}$ in 50 × $50 \mathrm{~m}$ na primeru terciarnega gričevja v Severovzhodni Sloveniji je pokazalo, da hektarske celice še manj verno prikazujejo relief kot je to primer $\mathrm{v}$ hribovitem delu Slovenije. Vendar pa menimo, da razlike med DMR $100 \times 100$ in DMR 50 × 50 le niso tako hude, da prvega ne bi mogli uporabiti pri obravnavanju splošnih značilnosti razširjenosti pojava, ki pokriva večje dele zemeljskega površja (npr. vinogradniških, sadjarskih ali gozdnih površin). Večje napake pa bi se pojavile pri analizi manjših površin (npr. vrtov, zazidalnih površin ipd.)

2. Morfometrijski elementi (s tem pa posredno tudi klimatski elementi) nam kažejo, da so vinogradniške površine omejene na termalni pas, znotraj tega pa na razširjenost vinogradov vplivajo tudi drugi, neklimatski dejavniki. Podatki kažejo, da ima največji vpliv na razširjenost vinogradov ekspozicija in relativna nadmorska višina. Rezultati kažejo, da strmejša pobočja, na katerih so za vinsko trto sicer ugodnejše klimatske razmere, niso zanimiva za sodobno strojno obdelavo. To še posebej velja za vinograde v družbeni lasti na območju Radgonsko-Kapelskih goric.

3. Zveza med klimatskimi bonitetami in dejansko razširjenostjo vinogradniških površin je $\mathrm{v}$ splošnem zelo visoka. Izjemo predstavljajo območja, kjer so lege vinogradniških površin narekovali družbenogeografski dejavniki (npr. lastništvo na sondnem območju na Mestnem Vrhu).

4. Karta bonitet vinogradniških površin je pokazala, da je s klimatskega vidika prvorazrednih vinogradniških površin na obeh sondnih območjih precej. Vendar pa taka slika ne sme zavajati. Za celovitejšo podobo kvali- 
tetnih vinogradniških površin bi morali upoštevati še litološki oziroma pedološki faktor.

5. Analiza primerjave vinogradniških površin na sondnih območjih med leti 1824 in 1985 je tudi pokazala, da se po trtni uši vinogradi niso vedno umikali $\mathbf{v}$ klimatsko ugodnejše lege. Strojna obdelava vinogradov v vertikali je povzročila celo umik vinogradov na pobočja $z$ manjšimi nakloni. Za ceno bolj ekonomične obdelave je zlasti družbeni sektor težil $\mathbf{k}$ večjim vinogradniškim kompleksom, pri čemer je širil vinogradniške površine tudi $v$ klimatsko manj primerne lege.

\section{VIRI IN LITERATURA}

Bat M., 1989: Fizična geografija gorskega sveta (na izbranih primerih), Magistrska naloga, Filozofska fakulteta, Oddelek za geografijo, Ljubljana

Colnarič J. et al., 1985: Posebno vinogradništvo, Biotehnična fakulteta, VTOZD za Agronomijo, Ljubljana

Gabrovec M., 1989: Vloga reliefa za geografsko podobo Polhograjskega hribovja, Magistrska naloga, Filozofska fakulteta, Oddelek za geografijo, Ljubljana

Gams I., 1972 a: Prispevek h klimatogeografski delitvi Slovenije, Geografski obzornik, XIX, Ljubljana

Gams I., 1972 b: Vprašanje klimatogeografske rajonizacije severovzhodne Slovenije. Geographica Slovenica, II, Ljubljana

Geiger R., 1966: Climate near the ground, Harvard University Press, Cambridge,

Geiger R., 1969: Topoclimates, v: General Climatology, Vol.2, Elsevier Publishing Company, Amsterdam-London-New York

Hočevar et al., 1982, Sončno obsevanje v Sloveniji, BTF, Ljubljana

Hočevar A., Rakovec J., 1979: Simulacija ekoloških razmer na pobočju in dnu idealizirane kotline ob povprečnem sončnem obsevanju na Dolenjskem, Zbornik BTF, Ljubljana

Hočevar A., Rakovec J., 1978: Simulacija ekoloških razmer na pobočju in dnu idealizirane kotline ob jasnem vremenu, Zbornik BTF, Ljubljana

Temeljni topografski načrti 1:5000 za območje Radgonskih goric in Mestnega Vrha 